\title{
Time From Hospital Admission to Onset of Septic Shock is Associated with Higher In-Hospital Mortality
}

\section{Ryota Sato}

Cleveland Clinic

\section{Siddharth Dugar ( $\nabla$ dugars@ccf.org )}

Cleveland Clinic

\section{Xiaozhen Han}

Cleveland Clinic

Matthew T. Siuba

Cleveland Clinic

\section{Simon Mucha}

Cleveland Clinic

Matthew Dettmer

Cleveland Clinic

Xiaofeng Wang

Cleveland Clinic

\section{Angel Coz Yataco}

Cleveland Clinic

Chirag Choudhary

Cleveland Clinic

\section{Ashish K. Khanna}

Wake Forest University School of Medicine, Atrium Health Wake Forest Baptist Health

\section{Abhijit Duggal}

Cleveland Clinic

\section{Research Article}

Keywords: sepsis, septic shock, late-onset, hospital-onset, outcomes

Posted Date: February 17th, 2022

DOI: https://doi.org/10.21203/rs.3.rs-1341356/v1 
License: (c) (i) This work is licensed under a Creative Commons Attribution 4.0 International License. Read Full License 


\section{Abstract}

\section{Objective:}

Several studies have shown septic shock developing later during the hospital stay are associated with greater mortality. However, the precise point at which time from hospital admission to the onset of septic shock (admission-shock-onset-time) becomes an independent prognostic marker of mortality remains unknown. This study aimed to evaluate the association between admission-shock-onset-time and inhospital mortality among patients with septic shock, as well as the optimal cut-off time period to categorize early and late-onset septic shock.

\section{Method:}

We conducted a single-center retrospective, observational cohort study at a quaternary academic hospital comprising adult patients with septic shock admitted to a medical intensive care unit (ICU) from 01/2011 to $12 / 2020$. A multivariable Cox regression model was developed to assess if log-transformed admissionshock-onset-time was associated with in-hospital mortality. A multivariable additive logistic regression was performed to estimate the odds ratio for mortality using the log-transformed admission-shock-onsettime. The thin plate spline function was used to describe the nonlinear relationship between the logtransformed admission-shock-onset-time and in-hospital mortality.

The primary outcome was in-hospital mortality and the secondary outcome was ICU mortality.

\section{Results:}

A total of 2,520 patients met the inclusion criteria with an overall in-hospital mortality of $37.3 \%$. The logtransformed admission-shock-onset-time was associated with higher in-hospital mortality [Hazard ratio (HR): 1.08, 95\% confidence interval (Cl): 1.05-1.11, p< 0.001] and ICU mortality (HR: 1.06, 95\%Cl: 1.03$1.10, p<0.001)$. This association remained significant after adjusting for clinical variables. The odds ratio for in-hospital mortality continued to increase throughout the observation period.

\section{Conclusion:}

In-hospital mortality continued to rise as admission-shock-onset-time increased in septic shock. No clear dichotomization between early and late septic shock can be ascertained and this categorization may limit our understanding of the temporal relationship of shock onset to mortality.

\section{Trial Registration}

This study was approved by Cleveland Clinic Institutional Review Board (IRB 15-1233).

\section{Background}


Septic shock is characterized by a dysregulated immune response triggered by an infection that requires vasopressor support to maintain systemic circulation [1-3]. This remains a major cause of health loss worldwide with an overall mortality approaching 40-60\% [4]. National and international committees have prioritized efforts to improve outcomes in sepsis by promoting early recognition and implementation of standardized therapeutic protocols $[5,6]$. However, current 3-and 6-hour bundles for sepsis management have largely been developed from studies conducted on patients presenting to emergency departments with sepsis [7, 8]. Patients developing sepsis and septic shock during their hospital stay have higher mortality compared to those who presented to the emergency department with sepsis [9-11].

Previous studies with small cohorts found patients with late-onset septic shock (defined as the onset of shock 24 hours or 48 hours after the intensive care unit (ICU) admission) had higher mortality than earlyonset septic shock [12-14]. These studies have thus proposed that the development of shock beyond the initial 48 hours thus plays an independent prognostic role in outcomes in septic shock. This arbitrary dichotomization of time at 24-48 hours implies a change in either patient or disease characteristics at the aforementioned time period with the associated difference in outcome in the latter group. It also erroneously implies that an increase in mortality associated with late-onset sepsis and septic shock is static. The primary objective of this study was to evaluate the temporal relationship of septic shock-onset from hospital admission (admission-shock-onset-time) and its association to in-hospital mortality in a larger cohort of patients with septic shock. We also aimed to determine if an optimal cut-off time period can distinguish early and late-onset septic shock.

\section{Methods}

We conducted a single-center, retrospective cohort study comprising of adult patients with septic shock who were admitted to the medical ICU at a large quaternary academic center between January 1, 2011, and December 31, 2020. Exclusion criteria included patients less than 18 years old, patients with sepsis but without septic shock, and patients transferred from other hospitals' ICU or general ward where hospital admission date and time cannot be determined accurately. Patients transferred directly from other hospitals' emergency departments to our medical ICU were included in this study. In cases of repeated admissions during the study period, only the first episode of sepsis or septic shock was included in the analysis. All clinical data were gathered from electronic medical records.

The 2001 American College of Chest Physicians/Society of Critical Care Medicine consensus criteria were used to define sepsis and septic shock. Septic shock was defined as all of the following: (i) a suspected or proven infection, (ii) at least two criteria of systemic inflammatory response syndrome, (iii) an acute circulatory failure requiring vasopressor support [15]. The common practice at our facility involves the initiation of vasopressors after adequate volume resuscitation to achieve mean arterial blood pressure of $\geq 65 \mathrm{~mm} \mathrm{Hg}$. However, given the retrospective nature of this study, the specific rationale for vasopressor initiation was at the discretion of individual providers. Admission-shock-onset-time was defined as the duration from the hospital admission to the time of initiation of vasopressor continuous infusion (either norepinephrine, vasopressin, epinephrine, or phenylephrine). Primary outcome was admission-shock- 
onset-time and in-hospital mortality. Secondary outcome was admission-shock-onset-time and ICU mortality.

We performed statistical analysis using R version 4.1.3 software (R Foundation for Statistical Computing) and SAS version 9.4 (SAS Institute, Inc.). Patients' characteristics were summarized by a median with interquartile range (IQR: 25th and 75th percentiles) for continuous variables. Frequencies and percentages were shown for categorical variables. We described the Poisson distribution of admission-shock-onset-time and the fraction of survival based on each time interval (every 1 hour and every 12 hours bin). Then, we compared two sequential time intervals to evaluate for any significant differences between each sequential time interval. We initially planned to use that as a cutoff to divide the admission-shock-onset-time into early-onset and late-onset if there were any significant differences. If there were not any such time intervals, we planned to use admission-shock-onset-time as a continuous variable. A multivariable Cox regression analysis with log transformation of admission-shock-onset-time was performed to calculate the hazard ratio (HR) of in-hospital mortality. The Cox regression model was adjusted based on a priori determined variables: age, sex, Acute Physiology And Chronic Health Evaluation (APACHE) III, history of chronic dialysis, cirrhosis, chronic obstructive lung disease (COPD), diabetes, immunosuppression, history of malignancy, maximum lactate level within 24 hours of shock onset, peak dose of norepinephrine equivalent dose within 24 hours of septic shock [16], total intravenous fluid administration within 24 hours of septic shock and time from septic shock to antibiotics administration. Missing values were imputed using the MissForest package, which is an iterative nonparametric imputation method based on a random forest [17]. It fits a random forest on the observed part and then predicts the missing part performing multiple imputation schemes by averaging over many unpruned classification or regression trees. A multivariable additive logistic regression was performed to estimate the odds ratio smooth function for the log-transformed admission-shock-onset-time [18]. The thin plate spline function was used for the nonlinear function of the log-transformed admission-shockonset-time. This study was approved by Cleveland Clinic Institutional Review Board (IRB 15-1233). In view of the retrospective nature of the study, the IRB waived the need for written informed consent. The study was performed in accordance with the ethical standards laid down in the 1964 Declaration of Helsinki and its later amendments.

\section{Results}

A total of 2,520 patients with septic shock were included in the analysis, as shown in Fig. 1 . The study population included 1,139 females (45.2\%), with the median age and APACHE III score being 64 years (IQR: 55-72) and 93 (IQR: 74-116), respectively. Patients' baseline characteristics, characteristics at ICU admission, and outcomes are shown in Table 1 . Of these, $51.7 \%$ of patients were directly admitted to ICU from the emergency department while $40.5 \%$ were transferred from general wards, $0.3 \%$ were from longterm care facilities, and $7.5 \%$ were from other admitting sources. $19.5 \%$ of patients developed acute kidney injury, while $46.9 \%$ of patients required invasive mechanical ventilation during their stay in ICU. ICU mortality was $29.5 \%$ and the overall in-hospital mortality was $37.3 \%$. Most patients who survived were discharged home or to skilled nursing facilities (Table 1). 
Table 1

Baseline and After-MICU admission characteristics.

\section{Baseline characteristics}

\begin{tabular}{|lc|}
\hline Age $($ Years $)$ & $64(55-72)$ \\
\hline Female & $1,139 / 2,520(45.2 \%)$ \\
\hline $\mathrm{BMI}\left(\mathrm{Kg} / \mathrm{m}^{2)}\right.$ & $27.3(23.0-33.0)$ \\
\hline Chronic dialysis & $378 / 2,520(15.0 \%)$ \\
\hline Cirrhosis & $394 / 2,520(15.6 \%)$ \\
\hline COPD & $606 / 2,52(24.0 \%)$ \\
\hline Diabetes & $759 / 2,520(30.1 \%)$ \\
\hline Immune Suppression & $835 / 2,520(33.1 \%)$ \\
\hline Malignancy & $718 / 2,520(28.5 \%)$ \\
\hline Characteristics on ICU admission & \\
\hline Admission to the medical ICU from & $1,304 / 2,520(51.7 \%)$ \\
Emergency department & $1,021 / 2,520(40.5 \%)$ \\
General wards & $188 / 2,520(7.8 \%)$ \\
\hline Others & \\
\hline APACHE III & $93(74-116)$ \\
\hline
\end{tabular}

BMI: body mass index

COPD: chronic obstructive pulmonary disease

APACHE: acute physiology and chronic health evaluation

IVF: intravenous fluid

CMS: Centers for Medicare and Medicaid

ICU: intensive care unit 


\section{Baseline characteristics}

Source of Infection

Pulmonary

Urinary tract

Intra-abdominal

Soft tissue

Gynecology

Others

Heart rate (beats/min)

Mean arterial pressure $(\mathrm{mmHg})$

Respiratory rate (/min)

Temperature (C)

White blood cell x $100\left(/ \mathrm{m}^{3}\right)$

Max. Lactate in 24 hours shock-recognition time

Total bolus IVF administration in 24 hours of shock-recognition time ( $\mathrm{ml}$ )

Total IVF administration in 24 hours of shock-recognition time ( $\mathrm{ml}$ )

Patient received CMS approved antibiotics prior to shock-onset time

Time from shock-onset time to antibiotics administration ( $\mathrm{min}$ )

Max norepinephrine dose in 24 hours of shock-onset time

\section{Outcomes}

In-hospital mortality

ICU-mortality

Acute Kidney Injury

BMI: body mass index

COPD: chronic obstructive pulmonary disease

APACHE: acute physiology and chronic health evaluation

IVF: intravenous fluid

CMS: Centers for Medicare and Medicaid

ICU: intensive care unit
$452(17.9 \%)$

$239(9.5 \%)$

$402(16.0 \%)$

$128(5.0 \%)$

$4(0.2 \%)$

$1,295(51.4 \%)$

$117(100-133)$

$53(47-59)$

$39(32-47)$

$36.6(36.3-37.3)$

$12.9(5.5-21.2)$

$2.9(1.6-5.5)$

1441 (591-3383)

$5,046(2,445-9,147)$

2,103 / 2,529 (83.2\%)

$-330(-1,170--30)$

$20.0(10.0-50.0)$

940 / 2,520 (37.3\%)

743 / 2,520 (29.5\%)

491 / 2,520 (19.5\%) 


\section{Baseline characteristics}

\begin{tabular}{ll} 
Norepinephrine duration (days) & $1.67(0.79-3.41)$ \\
\hline Hospital free-days (days) & $0(0-15.7)$ \\
\hline ICU free-days (days) & $20.1(0-24.4)$ \\
\hline Need for Invasive mechanical ventilation & $1,188 / 2,520(46.9 \%)$ \\
\hline Duration of mechanical ventilation (days) & $2.0(0.3-5.5)$ \\
\hline Discharge destination among survivors $(n=1,582)$ & $578 / 1,580(36.6 \%)$ \\
$\cdot$ Home & $225 / 1,580(14.2 \%)$ \\
$\cdot$ Long team acute care facility & $474 / 1,580(30.0 \%)$ \\
$\cdot$ Skilled care facility & $56 / 1,580(3.5 \%)$ \\
$\cdot$ Physical rehabilitation center & $223 / 1,580(14.1 \%)$ \\
$\cdot$ Hospice & $24 / 1,580(1.5 \%)$ \\
$\cdot$ Others &
\end{tabular}

BMl: body mass index

COPD: chronic obstructive pulmonary disease

APACHE: acute physiology and chronic health evaluation

IVF: intravenous fluid

CMS: Centers for Medicare and Medicaid

ICU: intensive care unit

Comparisons of likelihoods of in-hospital death according to both every one-hour intervals and every 12 hours intervals showed no significant differences when comparing two sequential time intervals (Supplementary File). We were unable to identify a distinct time interval, which could discriminate earlyfrom late-onset septic shock. Hence we proceeded with admission-shock-onset-time as a continuous variable.

In the multivariable Cox regression model, the log-transformed admission-shock-onset-time was associated with higher in-hospital mortality (HR: 1.08, 95\% Cl: 1.05-1.11, $\mathrm{p}<0.001)$ and ICU mortality (HR: $1.06,95 \% \mathrm{Cl}: 1.03-1.10, \mathrm{p}<0.001)$, as shown in Table 2. The adjusted odds ratio curve of the logtransformed admission-shock-onset-time for in-hospital mortality based on the additive logistic regression model is shown in Fig. 2. In this model, the baseline adjusted odds ratio was set at 1 hour of admission-shock-onset-time (zero in the log scale of the time). The odds ratio for in-hospital mortality continued to increase throughout the observation period. The adjusted odds ratio curve of the log- 
transformed admission-shock-onset-time for ICU mortality based on the additive logistic regression model is shown in Fig. 3. The adjusted odds ratio curves of the log-transformed admission-shock-onsettime admitted to the medical ICU from the emergency department and non-emergency department (hospital wards) showed a similar association to in-hospital mortality and admission-shock-onset-time. (Supplementary File). 
Table 2

Multivariable Cox regression analysis for in-hospital mortality and ICU-mortality.

\begin{tabular}{|c|c|c|c|}
\hline Factors & $\begin{array}{l}\text { HR for in-hospital } \\
\text { mortality }\end{array}$ & $95 \% \mathrm{Cl}$ & $\begin{array}{l}\mathrm{p}- \\
\text { value }\end{array}$ \\
\hline Log-transformed admission to shock-recognition time & 1.08 & $\begin{array}{l}1.05- \\
1.11\end{array}$ & $<.001$ \\
\hline Age & 1.01 & $\begin{array}{l}1.00- \\
1.01\end{array}$ & 0.012 \\
\hline Sex (Male) & 1.00 & $\begin{array}{l}0.87- \\
1.14\end{array}$ & 0.952 \\
\hline APACHE III & 1.01 & $\begin{array}{l}1.01- \\
1.01\end{array}$ & $\stackrel{<}{0.001}$ \\
\hline Chronic dialysis & 0.94 & $\begin{array}{l}0.78- \\
1.12\end{array}$ & 0.476 \\
\hline Cirrhosis & 1.15 & $\begin{array}{l}0.97- \\
1.37\end{array}$ & 0.102 \\
\hline COPD & 1.01 & $\begin{array}{l}0.86- \\
1.17\end{array}$ & 0.931 \\
\hline Diabetes & 0.94 & $\begin{array}{l}0.81- \\
1.08\end{array}$ & 0.382 \\
\hline Immune Suppression & 0.94 & $\begin{array}{l}0.79- \\
1.11\end{array}$ & 0.455 \\
\hline Malignancy & 1.30 & $\begin{array}{l}1.09- \\
1.56\end{array}$ & 0.004 \\
\hline Maximum lactate in 24 hours of shock $(\mathrm{mmol} / \mathrm{l})$ & 1.09 & $\begin{array}{l}1.04- \\
1.14\end{array}$ & 0.004 \\
\hline $\begin{array}{l}\text { Maximum NE equivalent dose in } 24 \text { hours of shock } \\
\text { ( } \mathrm{mcg} / \mathrm{min})\end{array}$ & 2.35 & $\begin{array}{l}2.17- \\
2.54\end{array}$ & $\dot{0} .001$ \\
\hline Total IVF administration in 24 hours of shock (ml) & 0.78 & $\begin{array}{l}0.72- \\
0.84\end{array}$ & $\dot{0.001}$ \\
\hline
\end{tabular}

HR: hazard ratio

$\mathrm{Cl}$ : confidence interval

APACHE: Acute Physiology And Chronic Health Evaluation

COPD: chronic obstructive lung disease

NE: norepinephrine

IVF: intravenous fluid 


\begin{tabular}{|c|c|c|c|}
\hline Factors & $\begin{array}{l}\text { HR for in-hospital } \\
\text { mortality }\end{array}$ & $95 \% \mathrm{Cl}$ & $\begin{array}{l}\mathrm{p}- \\
\text { value }\end{array}$ \\
\hline Time from shock to antibiotics time & 0.99 & $\begin{array}{l}0.99- \\
1.00\end{array}$ & 0.046 \\
\hline Factors & HR for ICU mortality & $95 \% \mathrm{Cl}$ & $\begin{array}{l}\mathrm{p}- \\
\text { value }\end{array}$ \\
\hline Log-transformed admission to shock-recognition time & 1.06 & $\begin{array}{l}1.03- \\
1.10\end{array}$ & $<.001$ \\
\hline Age & 1.00 & $\begin{array}{l}0.99- \\
1.01\end{array}$ & 0.419 \\
\hline Sex (Male) & 1.00 & $\begin{array}{l}0.86- \\
1.16\end{array}$ & 0.990 \\
\hline APACHE III & 1.01 & $\begin{array}{l}1.01- \\
1.02\end{array}$ & $<.001$ \\
\hline Chronic dialysis & 0.85 & $\begin{array}{l}0.68- \\
1.04\end{array}$ & 0.120 \\
\hline Cirrhosis & 1.05 & $\begin{array}{l}0.87- \\
1.26\end{array}$ & 0.647 \\
\hline COPD & 1.02 & $\begin{array}{l}0.86- \\
1.21\end{array}$ & 0.813 \\
\hline Diabetes & 1.02 & $\begin{array}{l}0.86- \\
1.20\end{array}$ & 0.803 \\
\hline Immune Suppression & 0.99 & $\begin{array}{l}0.82- \\
1.20\end{array}$ & 0.954 \\
\hline Malignancy & 1.15 & $\begin{array}{l}0.94- \\
1.40\end{array}$ & 0.177 \\
\hline Maximum lactate in 24 hours of shock ( $\mathrm{mmol} / \mathrm{l})$ & 1.18 & $\begin{array}{l}1.12- \\
1.25\end{array}$ & $\begin{array}{l}<.001 \\
0.001\end{array}$ \\
\hline $\begin{array}{l}\text { Maximum NE equivalent dose in } 24 \text { hours of shock } \\
(\mathrm{mcg} / \mathrm{min})\end{array}$ & 2.21 & $\begin{array}{l}2.01- \\
2.42\end{array}$ & $<.001$ \\
\hline
\end{tabular}

HR: hazard ratio

Cl: confidence interval

APACHE: Acute Physiology And Chronic Health Evaluation

COPD: chronic obstructive lung disease

NE: norepinephrine

IVF: intravenous fluid 


\begin{tabular}{|llll|}
\hline Factors & $\begin{array}{l}\text { HR for in-hospital } \\
\text { mortality }\end{array}$ & $95 \% \mathrm{Cl}$ & $\begin{array}{c}\text { p- } \\
\text { value }\end{array}$ \\
\hline Total IVF administration in 24 hours of shock $(\mathrm{ml})$ & 0.76 & $0.70-$ & $<$ \\
\hline Time from shock to antibiotics time & 0.99 & 0.83 & 0.001 \\
\hline HR: hazard ratio & & $0.99-$ & 0.153 \\
\hline Cl: confidence interval & & \\
\hline APACHE: Acute Physiology And Chronic Health Evaluation & \\
\hline COPD: chronic obstructive lung disease & & \\
\hline NE: norepinephrine & & \\
\hline IVF: intravenous fluid & & \\
\hline
\end{tabular}

\section{Discussion}

In this study, we demonstrate that in-hospital mortality increases as admission-shock-onset-time increases in patients with sepsis even after adjusting for comorbidities and baseline illness severity. Our study confirms that the timing of shock-onset in patients with sepsis during their hospital stay is independently associated with increased in-hospital mortality. But more importantly, we illustrated that the association between the timing of shock-onset and in-hospital mortality is continuous in nature without clear inflection points and there is a linear relationship between mortality and the time to shock onset during their stay in the hospital.

Our study is the first study to describe the temporal relationship between time to shock onset and mortality in sepsis. In previous studies, 24- and 48- hours from admission to ICU were used as arbitrary cut-offs to dichotomize septic patients into early-onset and late-onset septic shock showed the mortality rate to be 1.5 to 2 times higher in late-onset septic shock [12-14]. The arbitrary dichotomization of time at 24-48 hours implies a change in either patient or disease characteristics at the aforementioned time periods driving the higher mortality in the latter group [19]. In our study, we found mortality increased continuously with time to onset of septic shock from hospital admission implying thereby that mortality associated with this time duration is not a static phenomenon. Other authors have shown the onset of sepsis later during the hospital stay, defined with terms such as hospital-onset sepsis to be associated with higher mortality in comparison to community-acquired sepsis or septic shock $[9,10]$. In our subgroup analysis, we found a similar temporal relationship of in-hospital mortality to the onset of septic shock both in patients admitted to ICU with septic shock directly from the emergency department or from other admitting sources confirming that time to onset of septic shock is independently associated with mortality irrespective of where the patient is cared for at septic shock onset. 
The higher mortality in septic shock developing later in the course of hospital stay is likely multifactorial. Previous studies have shown the process of care variables including delays in recognition, antibiotic administration, intravenous fluid administration, and non-adherence to bundled care and vasoactive support may be responsible for an increase in mortality in septic shock [12, 20-22]. Patient-specific characteristics including severe comorbidities, underlying debilitation, and the development of organ dysfunction during the hospital course also may play a major role in driving this mortality. A longer hospital stay also puts this patient population at high risk for developing hospital-acquired infections with antibiotic-resistant organisms, which are associated with higher rates of mortality [23-25]. By considering the time to onset of septic shock as a continuous variable, future studies can inform on the specific mechanisms that contribute to this phenomenon.

The most obvious strength of this study is that this is the largest cohort of patients that have been assessed to study outcomes of sepsis based on the timing of septic shock onset [12-14]. In addition, to the best of our knowledge, this is the first study to suggest that the relationship between time to shock onset and mortality does not support the dichotomization of septic shock into "early" and "late". A previous study using two large national databases reported that patients with initially less severe sepsis made up the majority of sepsis-related deaths while most performance improvement efforts have been focused on the most severely ill patients [26]. Our study also supports the importance of future research to identify patients at high risk for developing septic shock later on in the course of their hospitalization and to identify and develop interventions to prevent the development of septic shock in this cohort.

We acknowledge that this study has limitations which are mainly results of its single-center, retrospective nature and reliance on electronic medical record documentation. To account for the inevitable risk of residual confounding, we performed multivariable analyses adjusting all known or suspected confounders. We also performed multiple imputations for missing values and ran subgroup analysis for a priori identified variables. Since this study was not designed to identify the reason for the delay in vasopressors, a delay in recognition of shock or delay in initiation of vasopressors by the bedside clinician might have resulted in residual confounding. However, we performed multivariable analyses adjusting for all known or suspected confounders and subgroup assessment showcasing similar trends. Therefore, we believe that the finding that the continuous nature of the relationship between admissionshock-onset-time and mortality is still likely to be the case despite these limitations. Secondly, we could not obtain the information on causative pathogens which in turn might have affected mortality [23]. Future analyses should evaluate the change in microbiology patterns in this group of patients and their association with mortality.

\section{Conclusion}

In this study, we demonstrated that time to onset of septic shock was independently associated with inhospital mortality. We also showed in-hospital mortality increased continuously and without dichotomization points as the time from hospital admission-shock-onset-time increased in patients with septic shock. Continued study is needed to identify the specific mechanisms responsible for this 
relationship in order to develop appropriate identification and management strategies in this patient population.

\section{Abbreviations List}

ICU

intensive care unit

IQR

interquartile range

HR

hazard ratio

APACHE III

Acute Physiology And Chronic Health Evaluation III

COPD

chronic obstructive lung disease

IRB

Institutional Review Board

\section{Declarations}

Ethics approval and consent to participate: This study was approved by Cleveland Clinic Institutional Review Board (IRB 15-1233) and waived the need for written informed consent. The study was performed in accordance with the ethical standards laid down in the 1964 Declaration of Helsinki and its later amendments.

Consent for publication: Consent for publication was waived because the data did not include individual details.

Competing interests: AKK consults for Edwards Lifesciences, Medtronic, Potrero Medical, GE Healthcare, Philips North America, Caretaker Medical and Retia Medical. He is funded by an NIH/NCATS KL2 award for assessment of blood pressure and oxygenation in postoperative patients and a Wake Forest Hypertension and Vascular Research award for studying the relationship between serum renin and outcomes in patients with septic shock. AD consults for ALung Technologies. He is funded by NHLBI U grant for the PETAL network to study prevention and treatment of acute lung injury. The rest of the authors declare that they have no competing interest.

Funding: None

Availability of data and materials: The datasets used and analyzed during the current study are available from the corresponding author on reasonable request. 
Author's contributions: RS, SD, AKK, and AD were responsible for conception of the article and drafted and revised the manuscript. MS, MD, SM, ACY, and CC contributed substantially to draft the manuscript. XH and XW contributed substantially to the study design, data analysis and interpretation. R.S. and S.D. contributed equally to the work and will share first co-authorship.

Acknowledgments: NA

\section{References}

1. Angus DC, van der Poll T: Severe sepsis and septic shock. The New England journal of medicine 2013, 369(9):840-851.

2. Singer M, Deutschman CS, Seymour CW, Shankar-Hari M, Annane D, Bauer M, Bellomo R, Bernard GR, Chiche JD, Coopersmith CM et al: The Third International Consensus Definitions for Sepsis and Septic Shock (Sepsis-3). Jama 2016, 315(8):801-810.

3. Cecconi M, Evans L, Levy M, Rhodes A: Sepsis and septic shock. Lancet 2018, 392(10141):75-87.

4. Rudd KE, Johnson SC, Agesa KM, Shackelford KA, Tsoi D, Kievlan DR, Colombara DV, Ikuta KS, Kissoon N, Finfer S et al: Global, regional, and national sepsis incidence and mortality, 1990\&\#x2013;2017: analysis for the Global Burden of Disease Study. The Lancet 2020, 395(10219):200-211.

5. Evans L, Rhodes A, Alhazzani W, Antonelli M, Coopersmith CM, French C, Machado FR, Mclntyre L, Ostermann M, Prescott HC et al: Surviving Sepsis Campaign: International Guidelines for Management of Sepsis and Septic Shock 2021. Critical care medicine 2021, 49(11):e1063-e1143.

6. Klompas M, Rhee C: The CMS Sepsis Mandate: Right Disease, Wrong Measure. Ann Intern Med 2016, 165(7):517-518.

7. Seymour CW, Gesten F, Prescott HC, Friedrich ME, Iwashyna TJ, Phillips GS, Lemeshow S, Osborn T, Terry KM, Levy MM: Time to Treatment and Mortality during Mandated Emergency Care for Sepsis. The New England journal of medicine 2017, 376(23):2235-2244.

8. Rhee C, Filbin MR, Massaro AF, Bulger AL, McEachern D, Tobin KA, Kitch BT, Thurlo-Walsh B, Kadar A, Koffman A et al: Compliance With the National SEP-1 Quality Measure and Association With Sepsis Outcomes: A Multicenter Retrospective Cohort Study. Critical care medicine 2018, 46(10):15851591.

9. Rhee C, Wang R, Zhang Z, Fram D, Kadri SS, Klompas M: Epidemiology of Hospital-Onset Versus Community-Onset Sepsis in U.S. Hospitals and Association With Mortality: A Retrospective Analysis Using Electronic Clinical Data. Critical care medicine 2019, 47(9):1169-1176.

10. Page DB, Donnelly JP, Wang HE: Community-, Healthcare, and Hospital-Acquired Severe Sepsis Hospitalizations in the University HealthSystem Consortium. Critical care medicine 2015, 43(9):1945-1951.

11. Jones SL, Ashton CM, Kiehne LB, Nicolas JC, Rose AL, Shirkey BA, Masud F, Wray NP: Outcomes and Resource Use of Sepsis-associated Stays by Presence on Admission, Severity, and Hospital Type. 
Med Care 2016, 54(3):303-310.

12. Roman-Marchant O, Orellana-Jimenez CE, De Backer D, Melot C, Vincent JL: Septic shock of early or late onset: does it matter? Chest 2004, 126(1):173-178.

13. Sakr Y, Vincent JL, Schuerholz T, Filipescu D, Romain A, Hjelmqvist H, Reinhart K: Early- versus lateonset shock in European intensive care units. Shock (Augusta, Ga) 2007, 28(6):636-643.

14. Huang CT, Tsai YJ, Tsai PR, Yu CJ, Ko WJ: Severe Sepsis and Septic Shock: Timing of Septic Shock Onset Matters. Shock (Augusta, Ga) 2016, 45(5):518-524.

15. Levy MM, Fink MP, Marshall JC, Abraham E, Angus D, Cook D, Cohen J, Opal SM, Vincent JL, Ramsay G: 2001 SCCM/ESICM/ACCP/ATS/SIS International Sepsis Definitions Conference. Critical care medicine 2003, 31(4):1250-1256.

16. Jentzer JC, Vallabhajosyula S, Khanna AK, Chawla LS, Busse LW, Kashani KB: Management of Refractory Vasodilatory Shock. Chest 2018, 154(2):416-426.

17. Stekhoven DJ, Bühlmann P: MissForest-non-parametric missing value imputation for mixed-type data. Bioinformatics 2012, 28(1):112-118.

18. Hastie T, Tibshirani R: Generalized Additive Models: Some Applications. Journal of the American Statistical Association 1987, 82(398):371-386.

19. Greenland S: Invited Commentary: The Need for Cognitive Science in Methodology. American Journal of Epidemiology 2017, 186(6):639-645.

20. Lundberg JS, Perl TM, Wiblin T, Costigan MD, Dawson J, Nettleman MD, Wenzel RP: Septic shock: An analysis of outcomes for patients with onset on hospital wards versus intensive care units. Critical Care Medicine 1998, 26(6):1020-1024.

21. Basheer A: Patients with hospital-onset sepsis are less likely to receive sepsis bundle care than those with community-onset sepsis. Evidence Based Nursing 2021, 24(3):99-99.

22. Baghdadi JD, Brook RH, Uslan DZ, Needleman J, Bell DS, Cunningham WE, Wong MD: Association of a Care Bundle for Early Sepsis Management With Mortality Among Patients With Hospital-Onset or Community-Onset Sepsis. JAMA Internal Medicine 2020, 180(5):707.

23. Vincent JL, Bihari DJ, Suter PM, Bruining HA, White J, Nicolas-Chanoin MH, Wolff M, Spencer RC, Hemmer M: The prevalence of nosocomial infection in intensive care units in Europe. Results of the European Prevalence of Infection in Intensive Care (EPIC) Study. EPIC International Advisory Committee. Jama 1995, 274(8):639-644.

24. Kumar A, Ellis P, Arabi Y, Roberts D, Light B, Parrillo JE, Dodek P, Wood G, Kumar A, Simon D et al: Initiation of inappropriate antimicrobial therapy results in a fivefold reduction of survival in human septic shock. Chest 2009, 136(5):1237-1248.

25. Koch AM, Nilsen RM, Eriksen HM, Cox RJ, Harthug S: Mortality related to hospital-associated infections in a tertiary hospital; repeated cross-sectional studies between 2004-2011. Antimicrobial Resistance and Infection Control 2015, 4(1). 
26. Liu V, Escobar GJ, Greene JD, Soule J, Whippy A, Angus DC, Iwashyna TJ: Hospital deaths in patients with sepsis from 2 independent cohorts. Jama 2014, 312(1):90-92.

\section{Figures}

\section{Figure 1.}

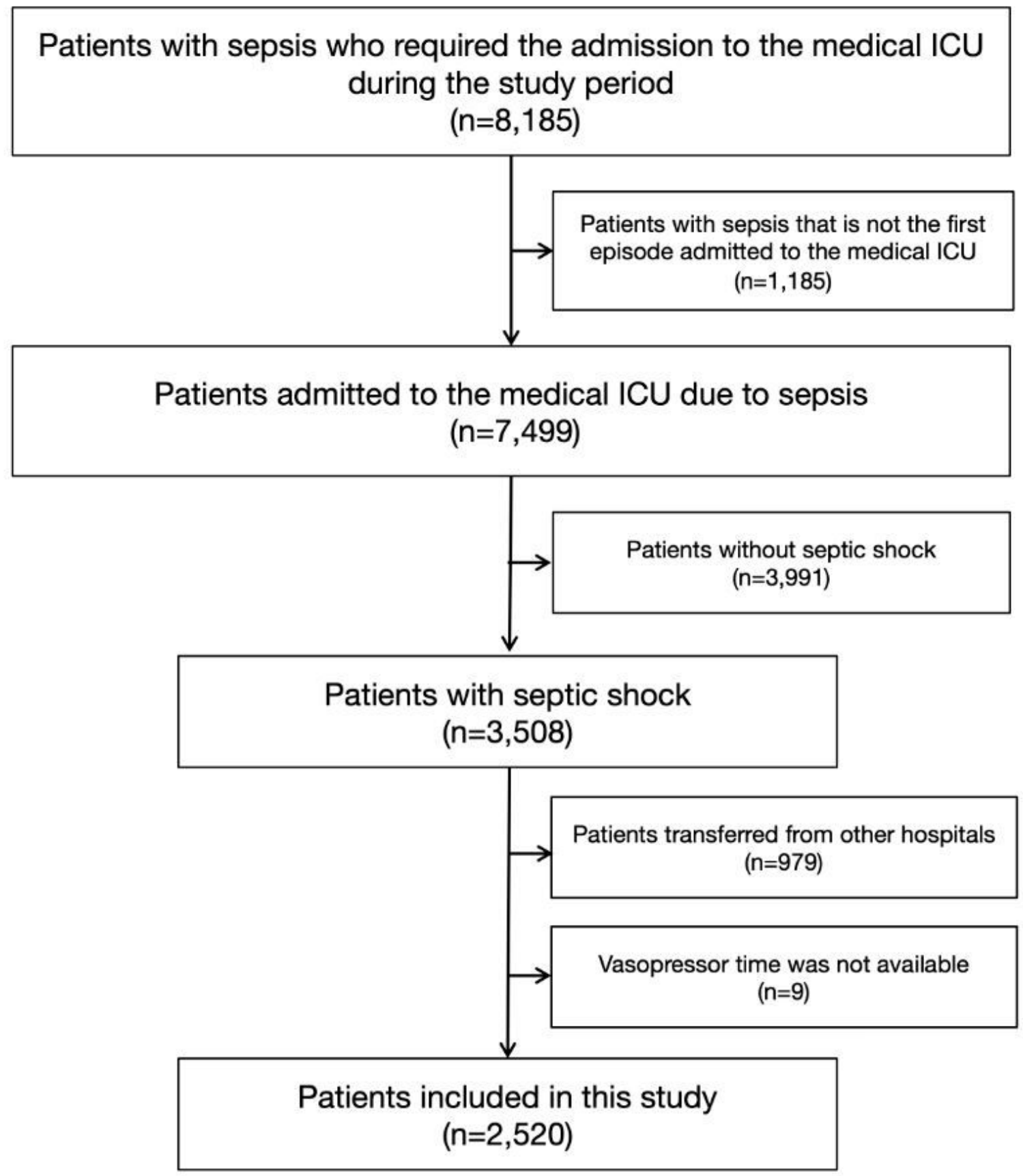

Figure 1 
A total of 8,185 patients with sepsis based on Sepsis-II criteria were admitted to medical intensive care unit (ICU) between January 1, 2011 and December 31, 2020. We excluded patients requiring readmission to ICU with sepsis or septic during the study period ( $\mathrm{n}=686$ patients), sepsis without septic shock $(\mathrm{n}=$ 3991 patients), admitted from other hospital ( $n=979$ patients) and patient where vasopressor initiation time cannot be accurately identified ( $n=9$ patients). Our final sample included 2520 patients.

\section{Adjusted Odds ratio for in-hospital mortality}

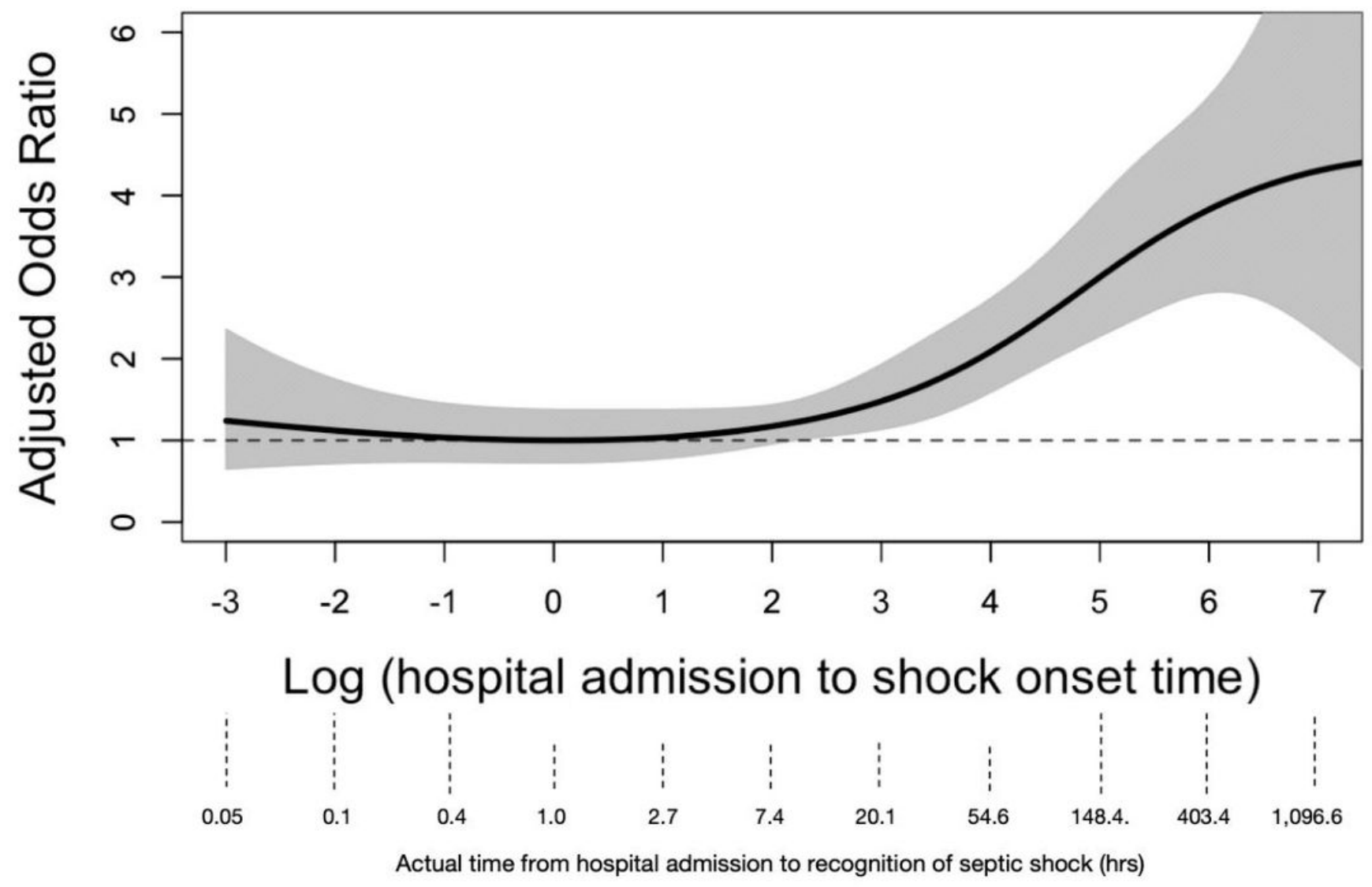

Figure 2

The odds ratio curve of the log-transformed admission-shock-onset-time for in-hospital mortality based on the additive logistic regression model. In this model, the baseline odds ratio was set at 1 hour of admission-shock-onset-time (zero in the log scale of the time). The odds ratio for in-hospital mortality continued to increase throughout the observation period. 


\section{Adjusted Odds ratio for ICU mortality}

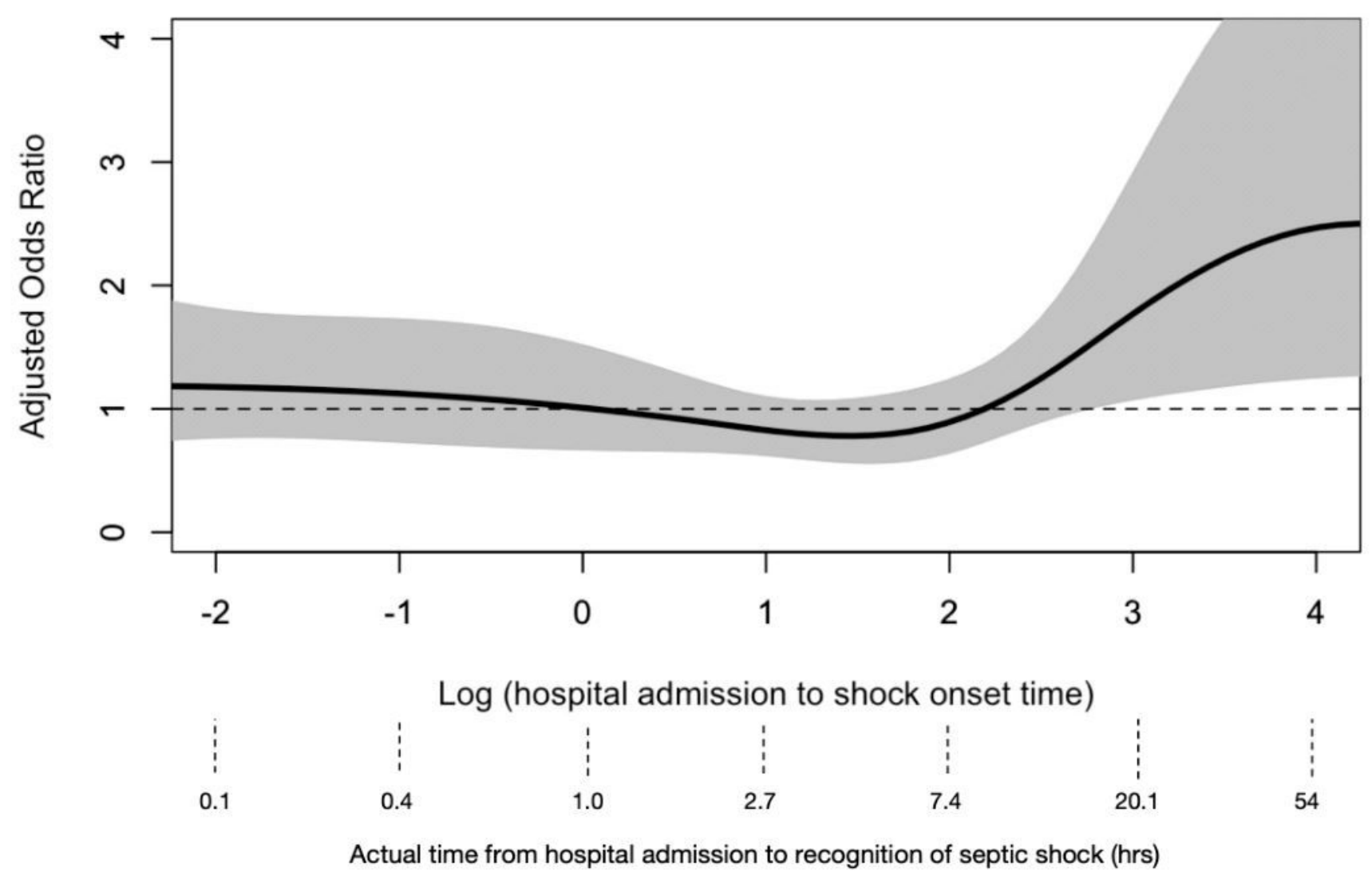

Figure 3

The odds ratio curve of the log-transformed admission-shock-onset-time for ICU mortality based on the additive logistic regression model. In this model, the baseline odds ratio was set at 1 hour of admissionshock-onset-time (zero in the log scale of the time). The odds ratio for in-hospital mortality continued to increase throughout the observation period.

\section{Supplementary Files}

This is a list of supplementary files associated with this preprint. Click to download.

- SupplementaryFile.docx 